\title{
Role of green tea in reduction of cardiovascular risk factors
}

This article was published in the following Dove Press journal:

Nutrition and Dietary Supplements

30 July 2010

Number of times this article has been viewed

\section{Nikolaos Alexopoulos Charalambos Vlachopoulos Christodoulos Stefanadis \\ Ist Cardiology Department, Athens Medical School, Hippokration Hospital, Athens, Greece}

Correspondence: Nikolaos Alexopoulos 5 Gladstonos Street, 15236, Penteli, Athens, Greece

Tel +306944272327

Fax +30 2106106258

Email nalexopoulos@hotmail.com

\begin{abstract}
Tea is widely consumed worldwide. There is accumulating evidence that tea consumption may be associated with reduced cardiovascular risk, an association that could be attributed to its flavonoid content. Green tea, the most common type of tea consumed in Asia, contains a large amount of nonoxidized flavonoids, named catechins. Green tea consumption has been associated with reduced incidence of cardiovascular mortality, stroke, and myocardial infarction. Although there is some inconsistency in the results, large, well-designed observational studies have shown this inverse association. However, the association of green tea with coronary artery disease is less well-established. The protective effect of green tea on cardiovascular events may be mediated by beneficial effects of green tea on various classical and novel cardiovascular risk factors. There is evidence that green tea reduces total and low-density lipoprotein (LDL) cholesterol and oxidized LDL cholesterol, enhances insulin sensitivity, and may prevent development of diabetes mellitus. There is also evidence that green tea reduces oxidative stress and reverses endothelial dysfunction. Its effect on blood pressure and arterial stiffness is confounded by the presence of caffeine, which has pressor and arterial stiffening effects, although this effect is probably counterbalanced by beneficial effects of other constituents in green tea. Green tea acutely increases blood pressure more than its caffeine content; the ingredients responsible for this are not known. On the other hand, green tea has a milder acute effect on arterial stiffness than its caffeine content. Its chronic effect on blood pressure and arterial stiffness may be neutral or even beneficial.
\end{abstract}

Keywords: antioxidants, blood pressure, cardiovascular mortality, green tea, myocardial infarction, stroke

Tea is the most consumed beverage worldwide aside from water. ${ }^{1}$ There are three main types of tea, all originating from the same species (Camellia sinensis), produced by different degrees of fermentation of tea leaves; black tea, where fermentation is high; green tea, where fermentation is very low; and oolong tea, where fermentation is intermediate. Black tea is the mainly consumed type of tea ( $76 \%$ to $78 \%$ worldwide), especially in the Western World; green tea is mainly consumed in Asia (20\% to $22 \%$ worldwide); and oolong tea has very low consumption (approximately $2 \%$ worldwide). ${ }^{1}$ Beyond these three main types, there are also other types of tea. One of them is red tea, which is consumed in small quantities and, like black tea, is also highly fermented, although its fermentation is a kind of zymosis caused by microorganisms, whereas the fermentation of black tea is due to an oxidation catalyzed by polyphenol oxidase, naturally occurring in tea leaves. ${ }^{2}$ Other types of tea include white and yellow tea, where tea leaves are harvested when they are still young, and they undergo no or little fermentation, respectively, thus they resemble green tea. 
There is accumulating evidence that black tea consumption may be associated with decreased cardiovascular risk, and this has been largely attributed to its polyphenolic content and its antioxidant properties. ${ }^{3}$ Recently, green tea has been the focus of extensive research; this interest has been driven by the fact that polyphenols present in green tea are not oxidized, in contrast with black tea, where polyphenols are oxidized during the fermentation process. ${ }^{4,5}$ Although not supported in all studies, this may imply a more potent antioxidant potential of green tea. In this review we present available data on the effect of green tea on cardiovascular performance and risk. Although it will focus specifically on green tea, the reader may also find scarce information on black tea, when needed to better illustrate the effects of green tea. Data on green tea composition, on its association with cardiovascular events and coronary artery disease, on the effect of green tea consumption on traditional cardiovascular risk factors, and on its effect on novel or less well-established risk factors, such as oxidant status, endothelial function, and arterial stiffness, will be presented.

\section{Green tea composition}

The chemical composition of green tea is complex; there are proteins ( $15 \%$ to $20 \%$ of dry weight) including enzymes, amino acids ( $1 \%$ to $4 \%$ of dry weight), carbohydrates (5\% to $7 \%$ of dry weight), lipids, such as linoleic and $\alpha$-linolenic acids, sterols, vitamins (B, C, E), xanthenes, such as caffeine and theophylline, pigments, such as chlorophyll and carotenoids, volatile compounds, such as aldehydes, and minerals and trace elements ( $5 \%$ of dry weight). ${ }^{2}$

Polyphenols dominate the chemistry of nonvolatile compounds in green tea and they represent $36 \%$ of dry weight of the green tea leaves. ${ }^{1,6}$ The polyphenols present in green tea are flavonoids; the largest proportion of them are flavan-3-ols, called catechins, such as (-)-epicatechin (6.4\% of total catechins), (-)-epicatechin-3-gallate $(13.6 \%$ of total catechins), (-)-epigallocatechin (19\% of total catechins), and (-)-epigallocatechin-3-gallate (59\% of total catechins, Figure 1). ${ }^{5}$ Green tea also contains gallic acid and other phenolic acids such as chlorogenic acid and caffeic acid, and flavonols such as kaempferol, myricetin, and quercetin. ${ }^{2}$ In contrast to green tea, which is steamed or pan-fired to inactivate polyphenol oxidase, black tea contains much smaller amount of catechins, due to their oxidation to dimers, ie, theaflavins, and to oligomers, ie, thearubigins, during the fermentation process (Figure 1)., The total amount of flavonoids in green and black tea is the same; the type of flavonoids (catechin monomers versus dimers and oligomers, respectively) is what differs. Green and oolong teas typically contain 30 to $130 \mathrm{mg}$ of epigallocatechin gallate per cup $(237 \mathrm{ml})$, while black teas may contain 0 to $70 \mathrm{mg}$ of epigallocatechin gallate per cup, depending on differences in the manufacturing method, the amount of tea used to prepare the tea beverage, the duration of infusion to hot water, the temperature of the water used, and other less important issues. ${ }^{7}$ The abovementioned great variations in flavonoid concentration among various green tea beverages, along with the differences in the volume that "a cup of tea" contains in various studies, poses difficulties in the quantification of a green tea beverage and its concentration in catechins, especially for comparisons among different studies.

Tea contains a significant amount of caffeine, which along with other xanthenes present in low quantities, comprise $3.5 \%$ of dry weight of green tea leaves. ${ }^{1}$ The concentration of caffeine in a tea beverage largely depends on the same parameters as those described for flavonoids; it is estimated that tea typically contains $40-60 \mathrm{mg}$ of caffeine per cup $(175 \mathrm{ml})$, whereas coffee typically contains $65-100 \mathrm{mg}$ of caffeine per $175 \mathrm{ml} .{ }^{8}$ Although there is great variability, there is usually less caffeine in green tea than in black tea, ${ }^{1,9}$

\section{Green tea consumption and cardiovascular events \\ Cardiovascular mortality}

The association of green tea consumption with total and cardiovascular mortality has been a topic of increasing interest during the last decade (Table 1). In the early prospective cohort studies, there were conflicting results; in one study of 8,552 Japanese adults, green tea consumption above 10 cups per day was associated with a $42 \%$ reduction in cardiovascular mortality only in males; ${ }^{10}$ in another study of 2,855 Japanese individuals, there was no association between green tea consumption and cardiovascular mortality. ${ }^{11}$ However, in the more recent, large, prospective Ohsaki study of 40,530 Japanese individuals, those consuming 5 or more cups of green tea per day had a $12 \%$ reduction in total and a $26 \%$ reduction in cardiovascular mortality compared to those consuming less than 1 cup per day. ${ }^{12}$ The decrease in cardiovascular mortality was larger in women than in men. This well-designed study demonstrated that the association of green tea consumption with reduced cardiovascular risk was independent of a great variety of possible confounders, such as age, job status, years of education, body mass index, physical activity, history of hypertension, diabetes, gastric ulcers, smoking status, alcohol intake, energy intake, and consumption of rice, soybean products, meat, fish, dairy products, fruits, vegetables, oolong tea, black tea, and coffee. 


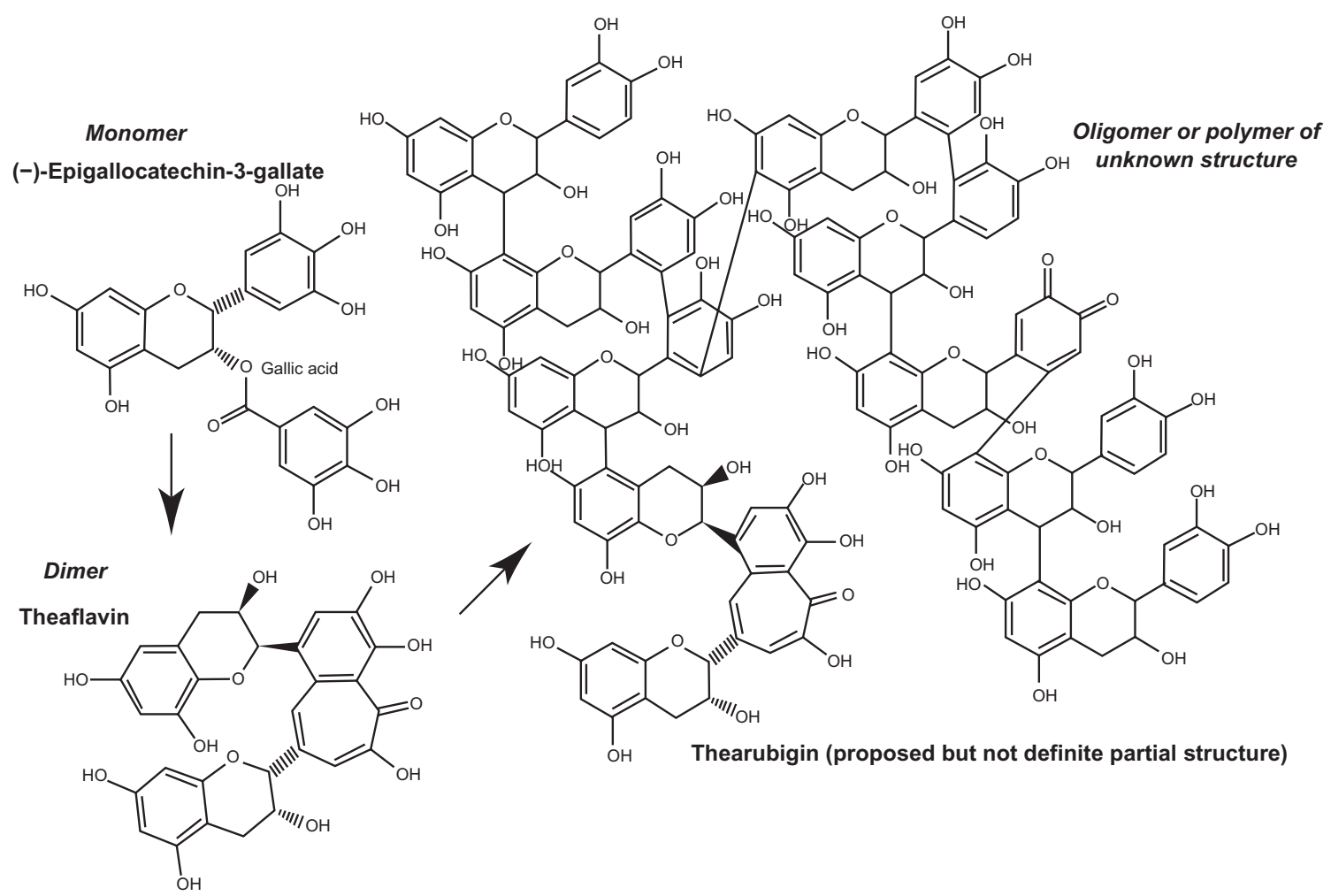

Figure I Structures of significant flavan-3-ols in tea. Green tea contains large amounts of catechins, like (-)-epigallocatechin-3-gallate (left upper). Black tea contains theaflavins, ie, catechin dimers, and thearubigins, ie, catechin oligomers of unknown structure. Theaflavins (left lower) and thearubigins (right) are produced from catechins, which are oxidized during the fermentation process of the fresh tea leaves. Copyright $\odot$ 2005. Reproduced with permission from Peterson J, Dwyer J, Bhagwat S, et al. Major flavonoids in dry tea.J Food Compost Anal. 2005; 18:487-501. ${ }^{5}$

\section{Stroke}

Both black and green tea consumption has been associated with decreased risk of stroke. In a cross-sectional study in China, the consumption of green tea was associated with lower risk of stroke; the odds ratio (OR) for consumption of more than $150 \mathrm{~g}$ per month of green tea was $0.35(95 \%$ CI: $0.18-0.72, P<0.01) .{ }^{13}$ In the abovementioned Ohsaki (cohort) study, ${ }^{12}$ the greatest reduction $(37 \%)$ in mortality associated with green tea consumption of equal or more than 5 cups per day compared to less than one cup per day was observed for stroke. In a previous study of middle-aged nonsmoking, nonalcohol-drinking women in Japan, the incidence of stroke and cerebral hemorrhage during a 4-year follow-up was two or more times higher in those who were consuming less than 5 cups of green tea daily, compared to those who were consuming 5 or more cups. ${ }^{14}$ Furthermore, the protective effect of both moderate (more than several cups every $2-3$ days but $<5$ cups every day) or high ( $\geq 5$ cups per day) green tea consumption on stroke has been demonstrated in another cohort study in middle-aged and elderly Japanese followed up for 5 years (multivariable HR, 0.43; 95\% confidence interval, $0.25-0.74 ; P=0.002$ and $0.41 ; 95 \%$ confidence interval, $0.24-0.70 ; P=0.001$, respectively). ${ }^{15}$
A recent meta-analysis has shown that, regardless of their country of origin, individuals consuming $\geq 3$ cups of tea per day have a $21 \%$ lower risk of stroke than those consuming $<1$ cup per day. ${ }^{16}$

\section{Myocardial infarction}

There is evidence that green tea consumption may be associated with reduced risk of myocardial infarction. In a study of 393 consecutive Japanese patients who underwent coronary angiography for suspected coronary artery disease, it was shown that green tea consumption of 1 or more cups per day was inversely associated with the incidence of myocardial infarction, independently of traditional risk factors and fruit or coffee intake. ${ }^{17}$ This observation is in line with previous observations of reductions in myocardial infarction incidence with tea consumption in Western countries, where black tea is the main tea consumed. ${ }^{18,19}$

\section{Green tea consumption and coronary artery disease}

The association of green tea consumption with the presence and extent of coronary artery disease is not yet known, since 
Table I Association of green tea consumption with cardiovascular mortality, stroke, myocardial infarction, and CAD

\begin{tabular}{|c|c|c|c|c|c|}
\hline Author, year & Population & $\begin{array}{l}\text { Type of } \\
\text { study }\end{array}$ & Follow-up & $\begin{array}{l}\text { Parameter } \\
\text { studied }\end{array}$ & Main findings \\
\hline Nakachi, $2000^{10}$ & $\begin{array}{l}8,552 \text { Japanese, over } \\
40 \text { years of age }\end{array}$ & Prospective & 13 years & CV mortality & $\begin{array}{l}\text { Green tea consumption above } 10 \text { cups per day } \\
\text { ( I } 50 \text { ml each) was associated with a } 42 \% \text { reduced } \\
\text { CV mortality only in males }\end{array}$ \\
\hline Iwai, 2002'I & $\begin{array}{l}2,855 \text { Japanese, } \\
\text { age } 40-79 \text { years }\end{array}$ & Prospective & 9.9 years & CV mortality & $\begin{array}{l}\text { No association between green tea consumption and } \\
\text { CV mortality }\end{array}$ \\
\hline Kuriyama, $2006^{12}$ & $\begin{array}{l}40,530 \text { Japanese, } \\
\text { age } 40-79 \text { years }\end{array}$ & Prospective & 7 years & $\begin{array}{l}\text { CV mortality, } \\
\text { stroke }\end{array}$ & $\begin{array}{l}\text { Those consuming } \geq 5 \text { cups ( } 100 \mathrm{ml} \text { each) per day } \\
\text { had } 26 \% \text { lower } C V \text { mortality compared to those } \\
\text { consuming }<I \text { cup per day. The greatest reduction } \\
(37 \%) \text { in } C V \text { mortality associated with green tea } \\
\text { consumption was observed for stroke }\end{array}$ \\
\hline Chen, $2004^{13}$ & $\begin{array}{l}14,212 \text { Chinese, } \\
\text { age } 35-60 \text { years }\end{array}$ & $\begin{array}{l}\text { Cross- } \\
\text { sectional }\end{array}$ & $\mathrm{N} / \mathrm{A}$ & Stroke & $\begin{array}{l}\text { Green tea consumption ( } 150 \mathrm{~g} \text { per month) was } \\
\text { associated with lower risk of stroke }\end{array}$ \\
\hline Sato, $1989^{14}$ & $\begin{array}{l}5,910 \text { nondrinking } \\
\text { and nonsmoking } \\
\text { women age } \geq 40 \text { years }\end{array}$ & Prospective & 4 years & Stroke & $\begin{array}{l}\text { The incidence of stroke and cerebral hemorrhage } \\
\text { was } \geq 2 \text { times in those who were consuming } \\
<5 \text { cups (of unspecified volume) per day, than in } \\
\text { those who were consuming } \geq 5 \text { cups/day }\end{array}$ \\
\hline Tanabe, $2008^{15}$ & $\begin{array}{l}\text { 6,358 Japanese, } \\
\text { age } 40-89 \text { years }\end{array}$ & Prospective & 5 years & Stroke & $\begin{array}{l}\text { Reduced incidence of stroke in those consuming } \\
\geq 5 \text { cups }(70-130 \mathrm{ml} \text { each) of green tea per day and in } \\
\text { those consuming several cups of green tea every } \\
2-3 \text { days (HR, } 0.43 ; 95 \% \mathrm{Cl}, 0.25-0.74 ; P=0.002 \text { and } \\
\mathrm{HR}, 0.4 \mathrm{I} ; 95 \% \mathrm{Cl}, 0.24-0.70 ; P=0.00 \mathrm{I} \text {, respectively) }\end{array}$ \\
\hline Hirano, $2002^{17}$ & $\begin{array}{l}393 \text { Japanese, } \\
\text { mean age } 63 \text { years }\end{array}$ & $\begin{array}{l}\text { Cross- } \\
\text { sectional }\end{array}$ & N/A & MI, CAD & $\begin{array}{l}\text { No association of green tea consumption with the } \\
\text { presence of CAD. The odds ratio for MI was } 0.58 \\
\text { ( } 95 \% \mathrm{Cl}, 0.34 \text { to } 0.98 \text { ) for a green tea intake of } \\
\geq \text { I cup (of unspecified volume) per day }\end{array}$ \\
\hline Sasazuki, $2000^{20}$ & $\begin{array}{l}5 \mathrm{I} 2 \text { Japanese, } \\
\text { age } \geq 30 \text { years }\end{array}$ & $\begin{array}{l}\text { Cross- } \\
\text { sectional }\end{array}$ & N/A & CAD & $\begin{array}{l}\text { In } 262 \text { males without diabetes, consumption of } \\
\geq 4 \text { cups (of unspecified volume) of } \\
\text { green tea per day had an odds ratio of } 0.4(95 \% \mathrm{Cl} \text {, } \\
0.2-0.9) \text { for the presence of CAD, as compared with } \\
\text { a consumption of } \leq \text { I cup per day }\end{array}$ \\
\hline
\end{tabular}

Abbreviations: $\mathrm{Cl}$, confidence interval; $\mathrm{CAD}$, coronary artery disease; $\mathrm{CV}$, cardiovascular; $\mathrm{HR}$, hazards ratio; $\mathrm{Cl}$, confidence interval; $\mathrm{MI}$, myocardial infarction; $\mathrm{N} / \mathrm{A}$, not applicable.

there is little consistent data available in the literature. In one study, consumption of green tea in males was associated with lower incidence of coronary artery disease, when patients with diabetes mellitus were excluded. The odds ratio of significant coronary stenosis for consumption of 4 or more cups per day was 0.4 (95\% confidence interval $0.2-0.9)$, respectively, as compared with a consumption of one cup per day or less. ${ }^{20}$ Notably, this association was not observed in females. In a previous study green tea consumption did not differ among patients with or without coronary artery disease. ${ }^{17}$

\section{Green tea consumption and traditional cardiovascular risk factors Blood pressure}

The effect of green tea consumption on blood pressure has been examined in various studies. Acutely, green tea increases blood pressure, as has been repeatedly shown., ${ }^{9,21,22}$ One of the ingredients in tea with an acute pressor effect is caffeine, ${ }^{23,24}$ however, the acute rise in blood pressure after tea consumption is greater than that of the same amount of caffeine ingested alone. It is not known which other tea ingredients are responsible for this. ${ }^{21}$ The studies on the short-term effect of green tea on blood pressure have revealed inconsistent results. A 2-month duration daily green tea consumption study did not show any pressor effect of green tea, ${ }^{25}$ whereas another study in overweight men showed that green tea consumption for two weeks decreased blood pressure, although this could have been the effect of the concomitant reduction in body weight. ${ }^{26}$ Finally, a study of obese children showed that green tea consumption for 24 weeks was accompanied by a decrease in blood pressure. ${ }^{27}$ The effect of daily consumption of capsules containing decaffeinated green tea has been recently studied in healthy volunteers; the authors reported significant blood pressure reductions after 3 weeks and 3 months. ${ }^{28}$

As it is generally believed in Eastern culture, ${ }^{29}$ green tea may exert antihypertensive effects in the long term, although no long-term intervention studies have been conducted so far 
and the results from cross-sectional studies do not uniformly imply such a pressure lowering effect. Green tea consumption has not been associated with blood pressure levels in a study of middle-aged (48-56 years old) Japanese men, ${ }^{30}$ whereas tea consumption (including both black and green tea) has been associated with reduced blood pressure in an Australian study of elderly women. ${ }^{31}$ We should emphasize, however, that in a meta-analysis of studies including all types of tea, tea consumption was not associated with reduced blood pressure. ${ }^{32}$ The most robust evidence of a possibly antihypertensive effect of green tea is derived from a cohort study in adults above 20 years of age, where green or oolong tea consumption was associated with reduced risk of developing hypertension in the follow-up, even after adjustment for a variety of confounders, such as age, sex, socioeconomic status, family history of hypertension, body mass index, waist-hip ratio, lifestyle factors (total physical activity, high sodium intake, cigarette smoking, alcohol consumption, and coffee drinking), and dietary factors (Figure 2). ${ }^{33}$

\section{Cholesterol}

There is accumulating evidence that green tea consumption reduces total and low-density lipoprotein (LDL) cholesterol. ${ }^{34}$ Epidemiological evidence from a Japanese population of individuals aged 40-69 years old, suggests that green tea consumption is associated with lower levels of total cholesterol. The association was found to be almost linear for up to 10 cups of tea per day, with a reduction of $0.015 \mathrm{mmol} / \mathrm{L}$ in total cholesterol for each cup of tea consumed both in men and women. ${ }^{35}$ On the other hand, green tea consumption was not associated with high-density lipoprotein (HDL) or triglycerides levels. ${ }^{35}$ The first randomized study of the effect of green tea extract consumption on lipid profile was published in $2003 ;{ }^{36}$ a green tea extract consumed daily for 12 weeks lowered total and LDL cholesterol in patients with mild to moderate hypercholesterolemia. ${ }^{36}$ A 24 week randomized placebo-controlled trial in 40 overweight Japanese children showed a significant reduction in LDL cholesterol with consumption of green tea. ${ }^{27}$ After 42 days, consumption of green tea caused a significant decrease in LDL in young female participants. ${ }^{37}$ In another study, 240 healthy participants were allocated either a beverage containing a green tea extract rich in catechins or a control beverage; after 12 weeks of continuous consumption, green tea extract reduced LDL cholesterol in comparison to the control beverage. ${ }^{38}$ The effect of daily consumption of capsules containing decaffeinated green tea for 3 weeks has been recently studied in healthy volunteers; although green tea had no effect on total cholesterol in the
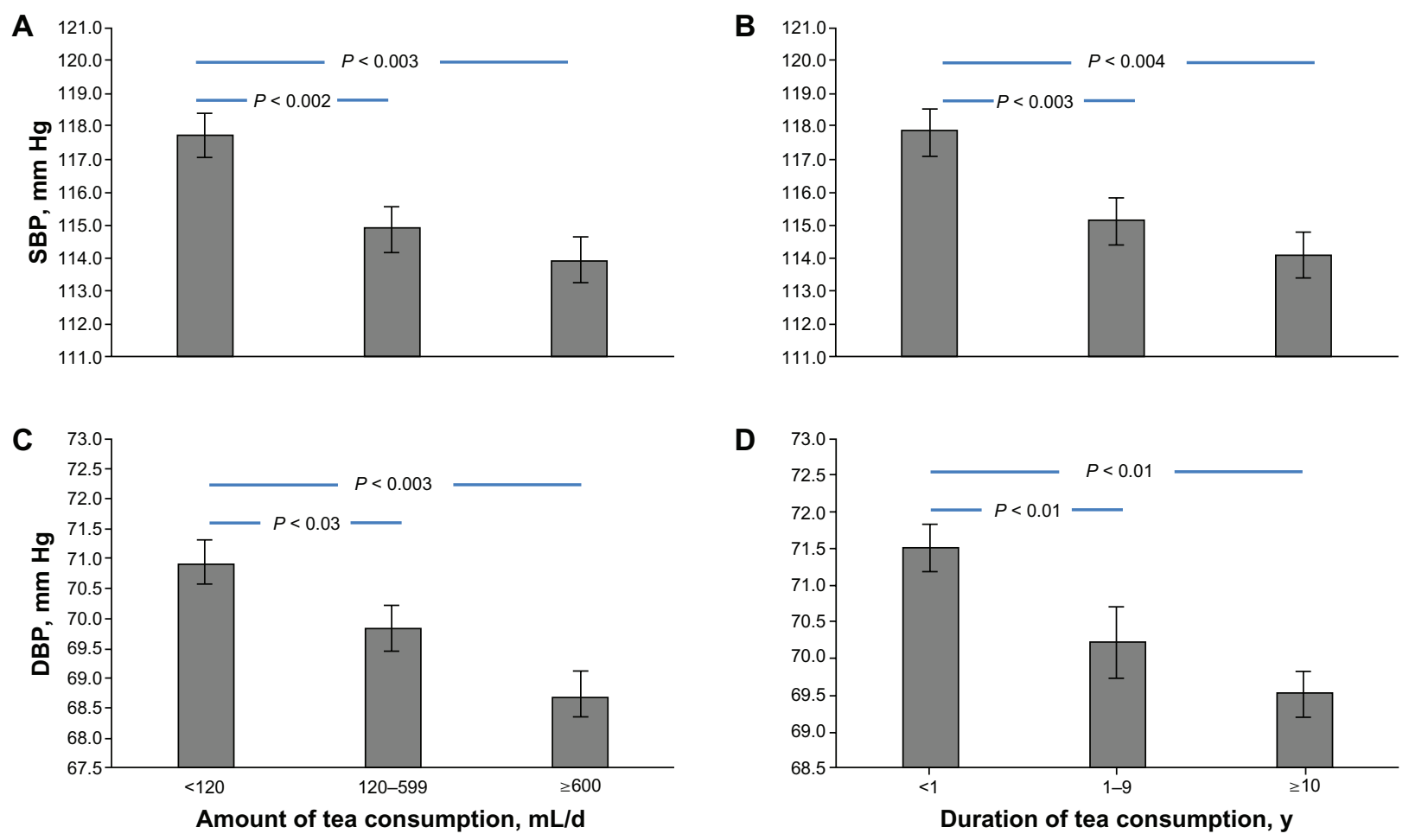

Figure 2 Dose-response effect between the amount and duration of tea consumption and blood pressure. There were significant differences in systolic (A) and diastolic (C) blood pressure between nonhabitual consumers and those consuming 120 to $599 \mathrm{~mL} / \mathrm{d}$ and $\geq 600 \mathrm{~mL} / \mathrm{d}$. There were also significant differences in systolic (B) and diastolic (D) blood pressure between nonhabitual consumers and those consuming tea for I to 9 years and $\geq 10$ years. Copyright $(\subset) 2004$. Modified with permission from Yang YC, Lu FH,Wu JS, Wu CH, Chang CJ.The protective effect of habitual tea consumption on hypertension. Arch Intern Med. 2004;164:1534-I540. ${ }^{33}$ 
whole study population, there were $10-$ and $9-\mathrm{mg} / \mathrm{dL}$ reductions in total and LDL cholesterol, respectively, in men, and there was $9 \mathrm{mg} / \mathrm{dL}$ lowering of total and LDL cholesterol in all participants with a baseline LDL cholesterol level greater than $99 \mathrm{mg} / \mathrm{dL}{ }^{28}$ However, LDL-lowering effects of green tea consumption have not been found in all studies. ${ }^{39,40}$

In line with the epidemiological studies, where there was no association between green tea consumption and HDL, green tea did not have any effect on HDL cholesterol in intervention studies. ${ }^{28,36-39}$

\section{Glucose metabolism}

There is evidence that suggests green tea enhances insulin sensitivity. ${ }^{41}$ The component largely responsible for this effect is epigallocatechin gallate, one of its main polyphenolic ingredients. ${ }^{41}$ Furthermore, epigallocatechin gallate reduces hepatic glucose production. ${ }^{42}$ There is evidence that green tea consumption is associated with lower glucose levels and reduced incidence of diabetes mellitus. A prospective study of more than 17,000 Japanese individuals, 40 to 65 years of age at baseline, without a history of type 2 diabetes, stroke, coronary heart disease, or cancer, demonstrated that the frequency of green tea consumption was inversely associated with the risk of new type 2 diabetes during a 5 -year follow-up. ${ }^{43}$ A subsequent smaller epidemiological study in Mediterranean Islands showed that daily tea consumption (all types included) was associated with lower glucose levels and reduced incidence of diabetes mellitus in non-obese but not in obese elderly participants. ${ }^{44}$ In the same study the results of the previous one were confirmed regarding the incidence of new diabetes mellitus during follow-up..$^{45}$ On the other hand, a recent study of healthy, middle-aged, Japanese males did not find any association between frequency of tea consumption and mean levels of blood glucose and hemoglobin A1c. ${ }^{46}$ The role of tea (all types included) in the prevention of type 2 diabetes mellitus development has been highlighted in two recent meta-analyses, where consumption of more than 3 to 4 cups per day of tea of any type was associated with reduced subsequent incidence of type 2 diabetes mellitus. ${ }^{47,48}$

Green tea acutely increases glucose metabolism and improves oral glucose tolerance test in healthy humans. ${ }^{49}$ However, these beneficial effects have not been verified in intervention studies of short- to middle-term green tea consumption. The daily supplementary intake of $500 \mathrm{mg}$ green tea polyphenols for 2 months did not have any clear effects on blood glucose level, hemoglobin A1c level, or insulin resistance in a small placebo-controlled study in Japanese individuals. ${ }^{25}$ Furthermore, daily consumption of $9 \mathrm{~g}$ of green tea for 4 weeks did not have any effect on glucose levels or insulin resistance in patients with type 2 diabetes; ${ }^{50}$ daily consumption of a green and black tea extract also did not have any effect on hemoglobin A1c level in middle-aged diabetics in another study. ${ }^{51}$ On the other hand, glucose levels were found to be lowered with daily oolong tea consumption for 30 days. ${ }^{52}$ These contradictory results do not allow firm conclusions to be drawn regarding the effect of green tea consumption on glucose metabolism.

\section{Green tea consumption and novel cardiovascular risk factors Antioxidant effect}

Oxidative stress is of paramount importance for the development of the atherosclerotic plaque. According to the oxidative modification hypothesis, LDL in its native state is not atherogenic. ${ }^{53}$ The oxidized LDL, however, is able to penetrate the arterial wall and to commence plaque formation. Oxidative stress has been assessed using various methods targeting different parameters of oxidative status.

There are several nutrients in green tea with antioxidant properties; apart from polyphenols, ie, catechins and gallic acid, other substances, such as ascorbic acid, tocopherols, carotenoids, and several minerals possess antioxidant properties. In vitro studies have confirmed the antioxidant properties of green tea using various techniques; the total antioxidant potential of green tea is higher than that of black tea using the ferric reducing power (FRAP) assay, ${ }^{54}$ the human plasma antioxidant capacity (TRAP), ${ }^{55}$ or the free radical-scavenging activity; ${ }^{56}$ on the other hand, theaflavins in black tea retained antioxidant capacity similar to that of green tea catechin monomers in some studies, ${ }^{57,58}$ while they inhibited the susceptibility of LDL cholesterol to oxidative modification more than catechins in another study; ${ }^{59}$ green tea has a much higher antioxidant activity against peroxyl radicals than garlic, kale, spinach, or Brussels sprouts, using the oxygen radical absorbance capacity (ORAC) assay; ${ }^{60}$ Epigallocatechin gallate, ie, the nutrient in green tea with the greatest antioxidant properties,${ }^{57}$ was found to be protective of the human erythrocyte membrane bound ATPase and to inhibit lipid peroxidation. ${ }^{61}$

Numerous studies have been aimed at examining the effect of green tea consumption on antioxidant status in humans; the detailed description of all these studies is beyond the scope of the present review. Although there are studies where there was no beneficial effect of green tea, ${ }^{22,62-64}$ it is believed that, in line with in vitro studies, green tea consumption acutely increases antioxidant capacity in humans, as this can be estimated 
using various techniques. ${ }^{55,65-67}$ The greatest increase in the antioxidant potential seems to appear 60 minutes after green tea consumption. ${ }^{66,67}$ This time-dependent effect, along with other methological issues, may account for the absence of observed effect in negative studies. The same beneficial results are observed after prolonged (short-or mid-term) green tea consumption. ${ }^{37,68,69}$

There is evidence that green tea reduces oxidized LDL in humans. In a study of 40 healthy adults, consumption of a green tea extract for 4 weeks significantly reduced oxidized LDL, although it had no effect on LDL levels. ${ }^{39}$ In a 4 week controlled dietary intervention, which included double blind supplementation with either green tea extract or placebo in 20 female participants, green tea extract had no specific effects on serum lipids, but it decreased plasma malondialdehyde, indicative of decreased lipid peroxidation. ${ }^{70}$ The same results were observed in 22 healthy male nonsmokers, in a 2 week green tea intervention study. ${ }^{71}$ The reduction in oxidized LDL with green tea consumption has also been shown in smokers. ${ }^{72}$ There are several other studies that support the reduction in oxidized LDL with green tea. ${ }^{40,73,74}$

\section{Endothelial function}

The endothelium is a layer separating the vessel wall from blood, with important homeostatic function. With a great number of substances, like nitric oxide, that it produces, it regulates arterial tone, the thrombotic/fibrinolytic state, vascular inflammation, cellular proliferation, and cellular apoptosis. $^{75}$ Through the imbalance that it induces, endothelial dysfunction is regarded as a critical step in the initiation and progression of atherosclerosis. ${ }^{76,77}$ Assessment of coronary endothelial function demands coronary artery catheterization and cannot be performed on a large scale; therefore, assessment of peripheral endothelial function is used instead. ${ }^{78}$ It has been shown that endothelial function assessed in the brachial artery is closely related to coronary endothelial function $^{79}$ and it predicts cardiovascular risk. Endothelial function is impaired in the presence of cardiovascular risk factors ${ }^{77}$ and it can be modified by a number of pharmacological and nonpharmacological means. ${ }^{80}$

The first observation that green tea improves endothelial function was reported in $2003 .{ }^{81}$ Thereafter, there have been several studies in which the effect of green tea consumption on endothelial function was examined. It has been shown, using strain gauge plethysmography, that green tea consumption reverses acute endothelial dysfunction in healthy smokers. ${ }^{82}$ In another study, consumption of green tea acutely improved acute endothelial function, assessed by postischemic brachial artery reactivity (flow-mediated dilatation), in healthy individuals, half of which were current smokers (Figure 3). ${ }^{22}$ A more recent study in healthy women reached the same conclusions regarding the beneficial effect of green tea on endothelial function. ${ }^{73}$ An interesting finding is that the effect of green tea on endothelial function seems to be comparable to that of black tea. ${ }^{83}$ The mid-term ( 2 weeks) effect of green tea on endothelial function has been examined in smokers; green tea increased brachial artery reactivity and circulating endothelial progenitor cells, both signs of reversal of endothelial dysfunction. ${ }^{84}$

The mechanisms of improved endothelial function (or, preferably, of reversal of endothelial dysfunction) with green tea consumption are not fully explored. It seems that flavonoids are the nutrients responsible for this effect; there is evidence that consumption of flavonoid-rich foods has a beneficial effect on endothelial function; ${ }^{85,86}$ epigallocatechin gallate has been shown to reverse endothelial dysfunction in patients with coronary artery disease. ${ }^{87}$ Mechanisms involved may include inhibition of angiotensin-converting enzyme activity by green tea polyphenols, ${ }^{88}$ increased nitric oxide production by endothelial cells, ${ }^{88}$ and improved endothelium-derived nitric oxide bioactivity. ${ }^{89}$ It seems that there is an interrelation between antioxidant and endothelial effects of green tea, although this has not been shown in all studies.

\section{Arterial stiffness and wave reflections}

The stiffness of large peripheral arteries is an important regulator of cardiovascular performance..$^{90}$ Increased arterial stiffness and wave reflections (ie, the sum of arterial waves that are reflected from the periphery towards the ascending

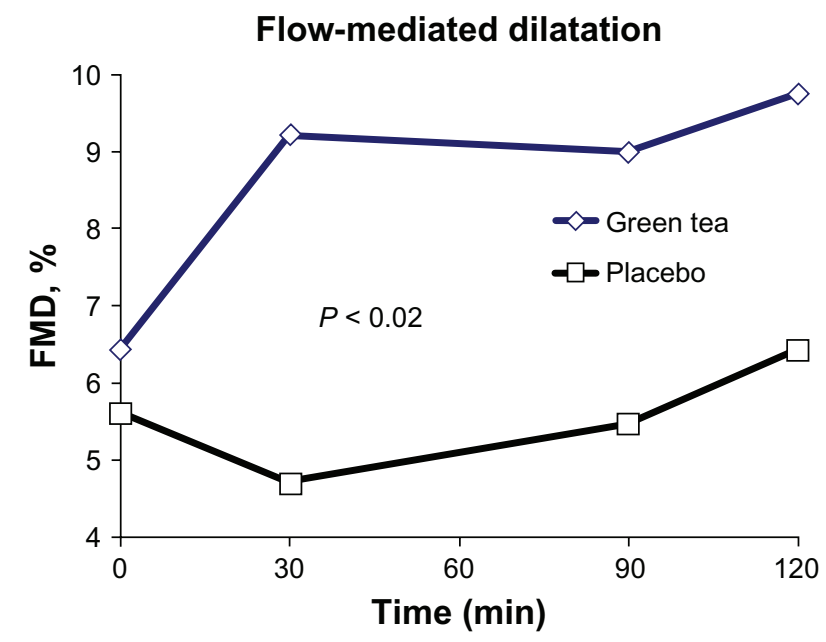

Figure 3 Acute effect of $6 \mathrm{gm}$ of green tea on endothelial function in healthy participants. Green tea increased flow-mediated (endothelium-dependent, postischemic) dilatation (FMD) of the brachial artery compared to placebo (hot water). 
aorta) are observed in the presence of cardiovascular risk factors for atherosclerotic disease and in patients with coronary artery disease and they have been identified as independent predictors of cardiovascular risk in a large variety of populations with or without disease and in the general population. ${ }^{91,92}$ Like endothelial function, arterial stiffness and wave reflections can also be modified by a large number of pharmacological and nonpharmacological means. ${ }^{93,94}$

The effect of green tea on arterial stiffness was first examined in patients with type 2 diabetes mellitus. The effect of green tea consumption for 4 weeks on brachial-ankle pulse wave velocity, ie, an index of arterial stiffness, was neutral. ${ }^{50}$ The effect of green tea consumption on arterial stiffness and wave reflections may be hampered by the presence of caffeine, a substance with well-documented stiffening effects. ${ }^{23,95-97}$ In a study where the acute effect of green tea consumption was compared to that of its caffeine content, it was shown that green tea had a neutral effect on arterial stiffness and it slightly increased wave reflections, whereas the effect of its caffeine content alone (ingested as caffeine capsules) was more prominent and more sustained (Figure 4). ${ }^{9}$ Unpublished data suggest that the short-term ( 2 weeks) effect of green tea consumption on arterial stiffness may be beneficial. ${ }^{98}$

The finding that flavonoid-rich foods with low or absent xanthine content reduce arterial stiffness and wave reflections implies that green tea catechins may account for the neutral effect of green tea on arterial stiffness and for its possibly beneficial short-term effect. ${ }^{99,100}$ On the other hand, green tea acutely increases blood pressure, which is a major determinant of arterial stiffness; ${ }^{92}$ as stated before, the acute increase in blood pressure is higher than the increase induced by its caffeine content, ${ }^{21}$ which implies that there may be other substances in green tea with blood pressure rising effects, and by that with stiffening properties. In the short-or long-term, the possible beneficial effects of green tea flavonoids on endothelial function and other cardiovascular risk factors, such as blood pressure and glucose metabolism, may account for the observed decrease in arterial stiffness and wave reflections.

\section{Conclusions and future directions}

Although green tea acutely increases blood pressure, and may increase indices of arterial wave reflections, this effect is probably only transient, since short-term consumption may have a neutral or opposite effect. On the other hand, green tea exerts a variety of beneficial metabolic effects with reductions in oxidative status and LDL oxidation, and amelioration of lipid and glucose metabolism. These effects are also accompanied by reversal of endothelial dysfunction. These effects may explain the independent inverse association of green tea with cardiovascular events, especially mortality and stroke, found in most observational studies, like in the large, prospective Ohsaki study of more than 40,000 individuals. Although not supported by all studies, the reduction in cardiovascular risk is larger in women than in men; however, this gender difference may be explained by other risk factors, such as smoking - more frequent in males - or menopause. As with all observational studies,

\section{Pulse wave velocity response}

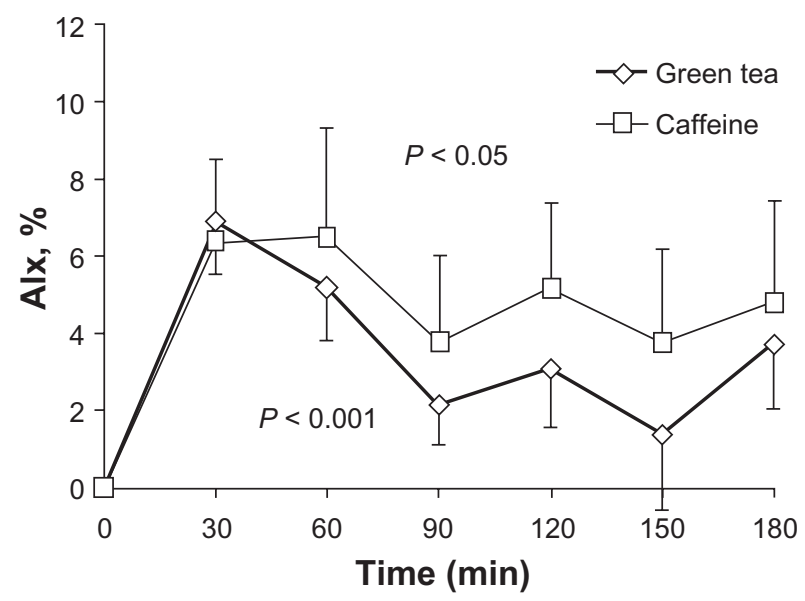

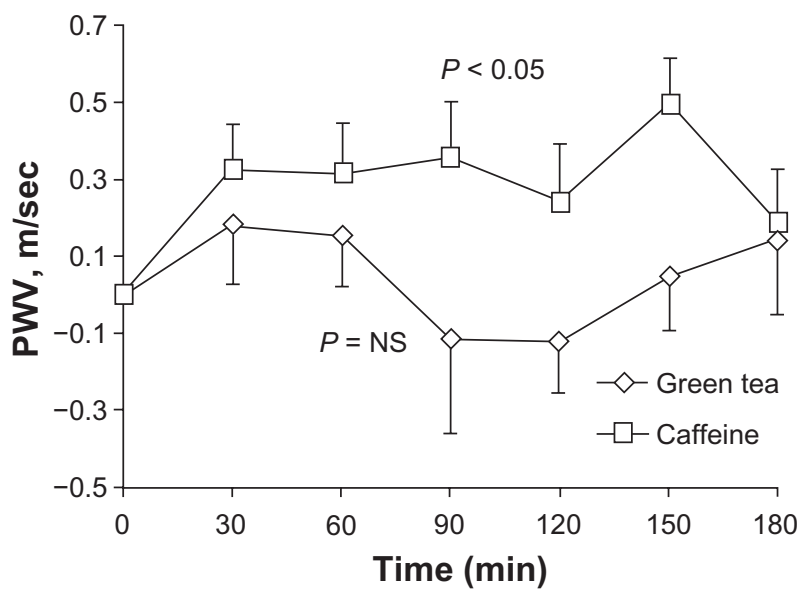

Figure 4 Acute effect of $6 \mathrm{gm}$ of green tea and its caffeine content (I25 mg) on pulse wave velocity (PWV, an index of arterial stiffness) and augmentation index (Alx, an index of wave reflections). Each graph represents the response of each variable, where response in the net effect of each intervention (green tea or caffeine) after the subtraction of the placebo effect. Green tea and caffeine increased augmentation index (left). Only caffeine, but not green tea, increased pulse wave velocity (right). Copyright @ 2006. Reproduced with permission from Vlachopoulos C, Alexopoulos N, Dima I, Aznaouridis K, Andreadou I, Stefanadis C. Acute effect of black and green tea on aortic stiffness and wave reflections. J Am Coll Nutr. 2006;25:216-223. ${ }^{9}$ 
we cannot exclude the possibility that the inverse association between green tea consumption and cardiovascular risk may be due to confounders not fully taken into account in statistical analyses. A large prospective interventional trial of green tea supplementation and adequate follow-up of individuals for hard events - or at least intermediate end-points such as indices of atherosclerosis - could help delineate the protective effect of green tea on cardiovascular risk.

\section{Disclosure}

The authors report no conflicts of interest in this work.

\section{References}

1. Graham HN. Green tea composition, consumption, and polyphenol chemistry. Prev Med. 1992;21:334-350.

2. Cabrera C, Artacho R, Gimenez R. Beneficial effects of green tea - a review. J Am Coll Nutr. 2006;25:79-99.

3. Hertog MG, Feskens EJ, Hollman PC, Katan MB, Kromhout D. Dietary antioxidant flavonoids and risk of coronary heart disease: the Zutphen Elderly Study. Lancet. 1993;342:1007-1011.

4. Higdon JV, Frei B. Tea catechins and polyphenols: health effects, metabolism, and antioxidant functions. Crit Rev Food Sci Nutr. 2003;43: 89-143.

5. Peterson J, Dwyer J, Bhagwat S, et al. Major flavonoids in dry tea. J Food Compost Anal. 2005;18:487-501.

6. Martin KR, Appel CL. Polyphenols as dietary supplements: a doubleedged sword. Nutrition and Dietary Supplements. 2010;2:1-12.

7. Balentine DA, Paetau-Robinson I. Tea as a source of dietary antioxidants with a potential role in prevention of chronic diseases. In: Mazza G, Oomah B edtiors. Herbs, Botanicals, and Teas. Lancaster: Technomic Publishing C., Inc.; 2000:265-287.

8. Everything you need to know about caffeine. International Food Information Council Foundation. Available at: http://www.foodinsight.org/ Content/6/caffeinebrochure.pdf. Accessed 04/18/2010.

9. Vlachopoulos C, Alexopoulos N, Dima I, Aznaouridis K, Andreadou I, Stefanadis C. Acute effect of black and green tea on aortic stiffness and wave reflections. J Am Coll Nutr. 2006;25:216-223.

10. Nakachi K, Matsuyama S, Miyake S, Suganuma M, Imai K. Preventive effects of drinking green tea on cancer and cardiovascular disease: epidemiological evidence for multiple targeting prevention. Biofactors. 2000;13: $49-54$.

11. Iwai N, Ohshiro H, Kurozawa Y, et al. Relationship between coffee and green tea consumption and all-cause mortality in a cohort of a rural Japanese population. J Epidemiol. 2002;12:191-198.

12. Kuriyama S, Shimazu T, Ohmori K, et al. Green tea consumption and mortality due to cardiovascular disease, cancer, and all causes in Japan: the Ohsaki study. JAMA. 2006;296:1255-1265.

13. Chen Z, Li Y, Zhao LC, et al. [A study on the association between tea consumption and stroke]. Zhonghua Liu Xing Bing Xue Za Zhi. 2004;25: 666-670.

14. Sato Y, Nakatsuka H, Watanabe T, et al. Possible contribution of green tea drinking habits to the prevention of stroke. Tohoku J Exp Med. 1989;157: 337-343.

15. Tanabe N, Suzuki H, Aizawa Y, Seki N. Consumption of green and roasted teas and the risk of stroke incidence: results from the Tokamachi-Nakasato cohort study in Japan. Int J Epidemiol. 2008;37: 1030-1040.

16. Arab L, Liu W, Elashoff D. Green and black tea consumption and risk of stroke: a meta-analysis. Stroke. 2009;40:1786-1792.

17. Hirano R, Momiyama Y, Takahashi R, et al. Comparison of green tea intake in Japanese patients with and without angiographic coronary artery disease. Am J Cardiol. 2002;90:1150-1153.
18. Geleijnse JM, Launer LJ, Van der Kuip DA, Hofman A, Witteman JC. Inverse association of tea and flavonoid intakes with incident myocardial infarction: the Rotterdam Study. Am J Clin Nutr. 2002;75: 880-886.

19. Peters U, Poole C, Arab L. Does tea affect cardiovascular disease? A meta-analysis. Am J Epidemiol. 2001;154:495-503.

20. Sasazuki S, Kodama H, Yoshimasu K, et al. Relation between green tea consumption and the severity of coronary atherosclerosis among Japanese men and women. Ann Epidemiol. 2000;10:401-408.

21. Hodgson JM, Puddey IB, Burke V, Beilin LJ, Jordan N. Effects on blood pressure of drinking green and black tea. J Hypertens. 1999;17: 457-463.

22. Alexopoulos N, Vlachopoulos C, Aznaouridis K, et al. The acute effect of green tea consumption on endothelial function in healthy individuals. Eur J Cardiovasc Prev Rehabil. 2008;15:300-305.

23. Vlachopoulos C, Hirata K, O'Rourke MF. Pressure-altering agents affect central aortic pressures more than is apparent from upper limb measurements in hypertensive patients: the role of arterial wave reflections. Hypertension. 2001;38:1456-1460.

24. Vlachopoulos C, Hirata K, Stefanadis C, Toutouzas P, O’Rourke MF. Caffeine increases aortic stiffness in hypertensive patients. $\mathrm{Am} \mathrm{J}$ Hypertens. 2003;16:63-66.

25. Fukino Y, Shimbo M, Aoki N, Okubo T, Iso H. Randomized controlled trial for an effect of green tea consumption on insulin resistance and inflammation markers. J Nutr Sci Vitaminol (Tokyo). 2005;51: $335-342$.

26. Nagao T, Komine Y, Soga S, et al. Ingestion of a tea rich in catechins leads to a reduction in body fat and malondialdehyde-modified LDL in men. Am J Clin Nutr. 2005;81:122-129.

27. Matsuyama T, Tanaka Y, Kamimaki I, Nagao T, Tokimitsu I. Catechin safely improved higher levels of fatness, blood pressure, and cholesterol in children. Obesity (Silver Spring). 2008;16:1338-1348.

28. Nantz MP, Rowe CA, Bukowski JF, Percival SS. Standardized capsule of Camellia sinensis lowers cardiovascular risk factors in a randomized, double-blind, placebo-controlled study. Nutrition. 2009;25:147-154.

29. Hu L. Medicinal tea and medicinal syrup. Traditional Chinese Medicine. Beijing, People's Republic of China: Ancient Books Press; 1986: $1-2$.

30. Wakabayashi K, Kono S, Shinchi K, et al. Habitual coffee consumption and blood pressure: A study of self-defense officials in Japan. Eur J Epidemiol. 1998;14:669-673.

31. Hodgson JM, Devine A, Puddey IB, Chan SY, Beilin LJ, Prince RL. Tea intake is inversely related to blood pressure in older women. J Nutr. 2003;133:2883-2886.

32. Taubert D, Roesen R, Schomig E. Effect of cocoa and tea intake on blood pressure: a meta-analysis. Arch Intern Med. 2007;167:626-634.

33. Yang YC, Lu FH, Wu JS, Wu CH, Chang CJ. The protective effect of habitual tea consumption on hypertension. Arch Intern Med. 2004;164: $1534-1540$.

34. Hooper L, Kroon PA, Rimm EB, et al. Flavonoids, flavonoid-rich foods, and cardiovascular risk: a meta-analysis of randomized controlled trials. Am J Clin Nutr. 2008;88:38-50.

35. Tokunaga S, White IR, Frost C, et al. Green tea consumption and serum lipids and lipoproteins in a population of healthy workers in Japan. Ann Epidemiol. 2002;12:157-165.

36. Maron DJ, Lu GP, Cai NS, et al. Cholesterol-lowering effect of a theaflavin-enriched green tea extract: a randomized controlled trial. Arch Intern Med. 2003;163:1448-1453.

37. Erba D, Riso P, Bordoni A, Foti P, Biagi PL, Testolin G. Effectiveness of moderate green tea consumption on antioxidative status and plasma lipid profile in humans. J Nutr Biochem. 2005;16:144-149.

38. Nagao T, Hase T, Tokimitsu I. A green tea extract high in catechins reduces body fat and cardiovascular risks in humans. Obesity (Silver Spring). 2007;15:1473-1483.

39. Inami S, Takano M, Yamamoto $\mathrm{M}$, et al. Tea catechin consumption reduces circulating oxidized low-density lipoprotein. International Heart Journal. 2007;48:725-732. 
40. Sung H, Min WK, Lee W, et al. The effects of green tea ingestion over four weeks on atherosclerotic markers. Ann Clin Biochem. 2005;42: 292-297.

41. Anderson RA, Polansky MM. Tea enhances insulin activity. J Agric Food Chem. 2002;50:7182-7186.

42. Waltner-Law ME, Wang XL, Law BK, Hall RK, Nawano M, Granner DK. Epigallocatechin gallate, a constituent of green tea, represses hepatic glucose production. $J$ Biol Chem. 2002;277:34933-34940.

43. Iso H, Date C, Wakai K, Fukui M, Tamakoshi A. The relationship between green tea and total caffeine intake and risk for self-reported type 2 diabetes among Japanese adults. Ann Intern Med. 2006;144: 554-562.

44. Polychronopoulos E, Zeimbekis A, Kastorini CM, et al. Effects of black and green tea consumption on blood glucose levels in non-obese elderly men and women from Mediterranean Islands (MEDIS epidemiological study). Eur J Nutr. 2008;47:10-16.

45. Panagiotakos DB, Lionis C, Zeimbekis A, et al. Long-term tea intake is associated with reduced prevalence of (type 2) diabetes mellitus among elderly people from Mediterranean islands: MEDIS epidemiological study. Yonsei Med J. 2009;50:31-38.

46. Maruyama K, Iso H, Sasaki S, Fukino Y. The Association between Concentrations of Green Tea and Blood Glucose Levels. J Clin Biochem Nutr. 2009;44:41-45.

47. Huxley R, Lee CM, Barzi F, et al. Coffee, decaffeinated coffee, and tea consumption in relation to incident type 2 diabetes mellitus: A systematic review with meta-analysis. Arch Intern Med. 2009;169: 2053-2063.

48. Jing Y, Han G, Hu Y, Bi Y, Li L, Zhu D. Tea consumption and risk of type 2 diabetes: a meta-analysis of cohort studies. J Gen Intern Med. 2009;24:557-562.

49. Tsuneki H, Ishizuka M, Terasawa M, Wu JB, Sasaoka T, Kimura I. Effect of green tea on blood glucose levels and serum proteomic patterns in diabetic $(\mathrm{db} / \mathrm{db})$ mice and on glucose metabolism in healthy humans. BMC Pharmacol. 2004;4:18.

50. Ryu OH, Lee J, Lee KW, et al. Effects of green tea consumption on inflammation, insulin resistance and pulse wave velocity in type 2 diabetes patients. Diabetes Res Clin Pract. 2006;71:356-358.

51. Mackenzie T, Leary L, Brooks WB. The effect of an extract of green and black tea on glucose control in adults with type 2 diabetes mellitus: double-blind randomized study. Metabolism. 2007;56:1340-1344.

52. Hosoda K, Wang MF, Liao ML, et al. Antihyperglycemic effect of oolong tea in type 2 diabetes. Diabetes Care. 2003;26:1714-1718.

53. Stocker R, Keaney JF Jr. Role of oxidative modifications in atherosclerosis. Physiol Rev. 2004;84:1381-1478.

54. Langley-Evans SC. Antioxidant potential of green and black tea determined using the ferric reducing power (FRAP) assay. Int $J$ Food Sci Nutr. 2000;51:181-188.

55. Serafini M, Ghiselli A, Ferro-Luzzi A. In vivo antioxidant effect of green and black tea in man. Eur J Clin Nutr. 1996;50:28-32.

56. Lee KW, Lee HJ, Lee CY. Antioxidant activity of black tea vs. green tea. J Nutr. 2002;132:785; author reply 786 .

57. Stewart AJ, Mullen W, Crozier A. On-line high-performance liquid chromatography analysis of the antioxidant activity of phenolic compounds in green and black tea. Mol Nutr Food Res. 2005;49:52-60.

58. Leung LK, Su Y, Chen R, Zhang Z, Huang Y, Chen ZY. Theaflavins in black tea and catechins in green tea are equally effective antioxidants. J Nutr. 2001;131:2248-2251.

59. Ishikawa T, Suzukawa M, Ito T, et al. Effect of tea flavonoid supplementation on the susceptibility of low-density lipoprotein to oxidative modification. Am J Clin Nutr. 1997;66:261-266.

60. Cao G, Sofic E, Prior RL. Antioxidant capacity of tea and common vegetables. Journal of Agricultural and Food Chemistry. 1996;44: 3426-3431.

61. Saffari Y, Sadrzadeh SM. Green tea metabolite EGCG protects membranes against oxidative damage in vitro. Life Sci. 2004;74: $1513-1518$.
62. Princen HM, van Duyvenvoorde W, Buytenhek R, et al. No effect of consumption of green and black tea on plasma lipid and antioxidant levels and on LDL oxidation in smokers. Arterioscler Thromb Vasc Biol. 1998; 18:833-841.

63. Hodgson JM, Croft KD, Mori TA, Burke V, Beilin LJ, Puddey IB. Regular ingestion of tea does not inhibit in vivo lipid peroxidation in humans. J Nutr. 2002;132:55-58.

64. Hodgson JM, Puddey IB, Croft KD, et al. Acute effects of ingestion of black and green tea on lipoprotein oxidation. Am J Clin Nutr. 2000;71: 1103-1107.

65. Benzie IF, Szeto YT, Strain JJ, Tomlinson B. Consumption of green tea causes rapid increase in plasma antioxidant power in humans. Nutr Cancer. 1999;34:83-87.

66. Serafini M, Laranjinha JA, Almeida LM, Maiani G. Inhibition of human LDL lipid peroxidation by phenol-rich beverages and their impact on plasma total antioxidant capacity in humans. J Nutr Biochem. 2000;11: 585-590.

67. Leenen R, Roodenburg AJ, Tijburg LB, Wiseman SA. A single dose of tea with or without milk increases plasma antioxidant activity in humans. Eur J Clin Nutr. 2000;54:87-92.

68. McKay DL, Blumberg JB. The role of tea in human health: an update. J Am Coll Nutr. 2002;21:1-13.

69. Klaunig JE, Xu Y, Han C, et al. The effect of tea consumption on oxidative stress in smokers and nonsmokers. Proc Soc Exp Biol Med. 1999;220: 249-254.

70. Freese R, Basu S, Hietanen E, et al. Green tea extract decreases plasma malondialdehyde concentration but does not affect other indicators of oxidative stress, nitric oxide production, or hemostatic factors during a high-linoleic acid diet in healthy females. Eur J Nutr. 1999;38: 149-157.

71. Hirano-Ohmori R, Takahashi R, Momiyama Y, et al. Green tea consumption and serum malondialdehyde-modified LDL concentrations in healthy subjects. J Am Coll Nutr. 2005;24:342-346.

72. Lee W, Min WK, Chun S, et al. Long-term effects of green tea ingestion on atherosclerotic biological markers in smokers. Clin Biochem. 2005;38: $84-87$.

73. Tinahones FJ, Rubio MA, Garrido-Sanchez L, et al. Green tea reduces LDL oxidability and improves vascular function. JAm Coll Nutr. 2008;27: 209-213.

74. Vinson JA, Teufel K, Wu N. Green and black teas inhibit atherosclerosis by lipid, antioxidant, and fibrinolytic mechanisms. Journal of Agricultural and Food Chemistry. 2004;52:3661-3665.

75. Widlansky ME, Gokce N, Keaney JF Jr, Vita JA. The clinical implications of endothelial dysfunction. $J$ Am Coll Cardiol. 2003;42: 1149-1160.

76. Biegelsen ES, Loscalzo J. Endothelial function and atherosclerosis. Coron Artery Dis. 1999;10:241-256.

77. Brunner H, Cockcroft JR, Deanfield J, et al. Endothelial function and dysfunction. Part II: Association with cardiovascular risk factors and diseases. A statement by the Working Group on Endothelins and Endothelial Factors of the European Society of Hypertension. J Hypertens. 2005;23:233-246.

78. Celermajer DS, Sorensen K, Ryalls M, et al. Impaired endothelial function occurs in the systemic arteries of children with homozygous homocystinuria but not in their heterozygous parents. J Am Coll Cardiol. 1993;22:854-858.

79. Anderson TJ, Uehata A, Gerhard MD, et al. Close relation of endothelial function in the human coronary and peripheral circulations. $J$ Am Coll Cardiol. 1995;26:1235-1241.

80. Ruilope LM, Redon J, Schmieder R. Cardiovascular risk reduction by reversing endothelial dysfunction: ARBs, ACE inhibitors, or both? Expectations from the ONTARGET Trial Programme. Vasc Health Risk Manag. 2007;3:1-9.

81. Murakami T, Ohsato K. Dietary green tea intake preserves and improves arterial compliance and endothelial function. J Am Coll Cardiol. $2003 ; 41: 271-274$ 
82. Nagaya N, Yamamoto H, Uematsu M, et al. Green tea reverses endothelial dysfunction in healthy smokers. Heart. 2004;90:1485-1486.

83. Jochmann N, Lorenz M, von Krosigk A, et al. The efficacy of black tea in ameliorating endothelial function is equivalent to that of green tea. Brit J Nutrition. 2008;99:863-868.

84. Kim W, Jeong MH, Cho SH, et al. Effect of green tea consumption on endothelial function and circulating endothelial progenitor cells in chronic smokers. Circ J. 2006;70:1052-1057.

85. Vlachopoulos C, Alexopoulos N, Stefanadis C. Effect of dark chocolate on arterial function in healthy individuals: cocoa instead of ambrosia? Curr Hypertens Rep. 2006;8:205-211.

86. Lekakis J, Rallidis LS, Andreadou I, et al. Polyphenolic compounds from red grapes acutely improve endothelial function in patients with coronary heart disease. Eur J Cardiovasc Prev Rehabil. 2005;12: 596-600.

87. Widlansky ME, Hamburg NM, Anter E, et al. Acute EGCG supplementation reverses endothelial dysfunction in patients with coronary artery disease. J Am Coll Nutr. 2007;26:95-102.

88. Persson IA, Josefsson M, Persson K, Andersson RG. Tea flavanols inhibit angiotensin-converting enzyme activity and increase nitric oxide production in human endothelial cells. J Pharm Pharmacol. 2006;58: 1139-1144.

89. Fitzpatrick DF, Hirschfield SL, Ricci T, Jantzen P, Coffey RG. Endothelium-dependent vasorelaxation caused by various plant extracts. J Cardiovasc Pharmacol. 1995;26:90-95.

90. Vlachopoulos C, Aznaouridis K, Stefanadis C. Clinical appraisal of arterial stiffness: the Argonauts in front of the Golden Fleece. Heart. 2006;92: $1544-1550$.

91. Agabiti-Rosei E, Mancia G, O’Rourke MF, et al. Central blood pressure measurements and antihypertensive therapy: a consensus document Hypertension. 2007;50:154-160.
92. Laurent S, Cockcroft J, Van Bortel L, et al. Expert consensus document on arterial stiffness: methodological issues and clinical applications. Eur Heart J. 2006;27:2588-2605.

93. Stefanadis C, Tsiamis E, Vlachopoulos C, et al. Unfavorable effect of smoking on the elastic properties of the human aorta. Circulation. 1997;95: 31-38.

94. Giannattasio C, Failla M, Calchera I, et al. Pharmacological improvement of large arteries properties. Pathol Biol (Paris). 1999;47:744-751.

95. Vlachopoulos C, Hirata K, O'Rourke MF. Effect of caffeine on aortic elastic properties and wave reflection. $J$ Hypertens. 2003;21: 563-570.

96. Vlachopoulos C, Panagiotakos D, Ioakeimidis N, Dima I, Stefanadis C. Chronic coffee consumption has a detrimental effect on aortic stiffness and wave reflections. Am J Clin Nutr. 2005;81:1307-1312.

97. Vlachopoulos CV, Vyssoulis GG, Alexopoulos NA, et al. Effect of chronic coffee consumption on aortic stiffness and wave reflections in hypertensive patients. Eur J Clin Nutr. 2007;61:796-802.

98. Alexopoulos N, Vlachopoulos C, Baou K, et al. The short-term effect of tea consumption on aortic stiffness and wave reflections. American College of Cardiology Congress. Orlando, FL; 2009.

99. Teede HJ, McGrath BP, DeSilva L, Cehun M, Fassoulakis A, Nestel PJ. Isoflavones reduce arterial stiffness: a placebo-controlled study in men and postmenopausal women. Arterioscler Thromb Vasc Biol. 2003;23: 1066-1071.

100. Vlachopoulos CV, Alexopoulos NA, Aznaouridis KA, et al. Relation of habitual cocoa consumption to aortic stiffness and wave reflections, and to central hemodynamics in healthy individuals. Am J Cardiol. 2007;99: $1473-1475$.
Nutrition and Dietary Supplements

\section{Publish your work in this journal}

Nutrition and Dietary Supplements is an international, peer-reviewed, open access journal focusing on research into nutritional requirements in health and disease, impact on metabolism and the identification and optimal use of dietary strategies and supplements necessary for normal growth and development. The journal welcomes papers covering

\section{Dovepress}

original research, basic science, clinical \& epidemiological studies, reviews and evaluations, guidelines, expert opinion and commentary, case reports and extended reports. The manuscript management system is completely online and includes a very quick and fair peer-review system, which is all easy to use.

Submit your manuscript here: http://www.dovepress.com/nutrition-and-dietary-supplements-journal 